\title{
COMPUTATIONAL TECHNIQUE FOR MODELING AND CLUSTERING OF FEEDBACK CONTROL IN GALAXIES USING GRAVITATIONAL THERMODYNAMICS
}

\author{
ANKUSH RAI*, JAGADEESH KANNAN R \\ School of Computing Science \& Engineering, VIT University, Chennai, Tamil Nadu, India. Email: ankushressci@gmail.com
}

Received: 28 December 2016, Revised and Accepted: 10 May 2017

\begin{abstract}
A model for clustering of galaxies through relativistic gravitational thermodynamics is laid on. Unlike the theories presented which consist of point mass system in expanding universe, we presented the methodology, in which partial differential equation and thermodynamic equations with the
\end{abstract} equation of state in accord with gravitational interaction between particles to study extended structures of universe.

Keywords: Computing Technique, Modelling, Feedback Control.

(C) 2017 The Authors. Published by Innovare Academic Sciences Pvt Ltd. This is an open access article under the CC BY license (http://creativecommons. org/licenses/by/4. 0/) DOI: http://dx.doi.org/10.22159/ajpcr.2017.v10s1.19983

\section{INTRODUCTION}

Galaxies cluster on very large scales under the influence of their mutual gravitation and the characterization of this clustering is a problem of current interest. Observations indicate that while the large-scale distribution of galaxies appears to be essentially uniform, however, small-scale distribution is appreciably influenced by the well-known tenancy toward clustering. The universe is homogeneous and isotropic on scales $\geq 100-200 \mathrm{Mpc}$, whereas on smaller scales, its fundamental units - galaxies cluster together to form groups, clusters, and even superclusters.

It is ascertained that copious fraction of cosmological theories of many body problems has been developed mainly from a thermodynamic point of view. Herein, we have abided the same approach and employed the equations of the state along with the correlation functions for the development of a theoretical model. Our universe emerged from a singularity at a very high temperature about $2 \times 10^{10}$ years ago. At such temperatures, all matter behaves like photons; hence, the initial state was a chaotic gaseous inferno of high-energy elementary particles and photons. As the universe expanded, the temperature dropped and the heavier particles annihilated and decayed into the less massive stable particles (protons, neutrons, and neutrinos). Hence, in the same pursuit, we derive the entropy differential equation from relativistic kinematics of inertial and gravitational mass where the application of gravitational thermodynamics in the clustering of galaxies has been discussed on the basis of N-body computation techniques.

We derived the relation the value of $\mathrm{b}$ which is the ratio of gravitational correlation energy to twice kinetic energy measures two-point correlation function $\xi 2$ and depends on the average number density - $n$, temperature - T, and the interparticle distance - $r$. Thus, it is valuable to understand the functional form of $\xi 2$ which depends on the value of $b(n, T)$. The two partial differential equations developed for the galaxy clusters (with point mass and extended mass structures) in an expanding universe provide a new approach for understanding the phenomena. Simulation is performed using methods mentioned in Matsubara and Rai [10-15].

\section{RELATIVISTIC THERMODYNAMICS}

In classical mechanics as well as in special theory of relativity, the mass at coordinates in space has a direct physical meaning. To say that, a mass at a point $\mathrm{P}$ in a space means the projection of the event by $\mathrm{m}$ at $\mathrm{P}$ on the axis of the dimensions. Furthermore, there is a standard clock time $\mathrm{t}$ associated with the event at $\mathrm{P}$ where $\mathrm{m}$ is the cause of the event. The action for a free particle is given by:

$$
S=-\alpha \int_{a}^{0} d s
$$

Where $\alpha$ is the quantity which characterizes the particle.

Applying relativistic mechanics, the action can be written in the form:

$$
S=\int_{t 1}^{t 2} L d t=-\int_{t 1}^{t 2} \alpha c \sqrt{1-\left(\frac{v}{c}\right)^{2}} d t
$$

Where, $\mathrm{L}$ is the Lagrange's function and represented as $\mathrm{L}=-\alpha \mathrm{c} \sqrt{1-\left(\frac{\mathrm{v}}{\mathrm{c}}\right)^{2}}$. From the remnant of preconceived notion of classical mechanics, the determined Lagrange's function for a free particle is $\mathrm{L}=a v^{2} . \mathrm{v}$ is the speed of the particle and a is a hypothetical quantity which is given as $\mathrm{a}=\mathrm{m} / 2$. Here, $\mathrm{m}$ is the mass of the particle. The results of our measuring of $m$ are verifications of the indistinguishable about the kind of mass (whether it is gravitational mass $\mathrm{m}_{\mathrm{g}}$ or inertial mass $m_{i}$ ).

If the limit $\mathrm{c} \rightarrow \infty$, the correlation between a and $\alpha$ can be expressed below. Where relativistic expression $\mathrm{L}$ is reduced to the classical expression.

$\mathrm{L}=\mathrm{a} \mathrm{v}^{2}$ (classical expression),

$\mathrm{L} \mathrm{a} \mathrm{v}^{2} / 2 \mathrm{c}$ (relativistic expression)

Now, if $\alpha=2 \mathrm{ac}=\mathrm{mc}$, we get,

$\mathrm{L}=\mathrm{a} \mathrm{v}^{2}$. Following the first axiom given, we will have $\mathrm{m}=\mathrm{m}_{\mathrm{g}}$. Therefore, $\mathrm{a}=\mathrm{m}_{\mathrm{g}} / 2$.

The generalized expression for the action for a free particle is of the form:

$$
S=-m_{g} c \int_{a}^{b} d s
$$


Or $S=-\int_{t 1}^{t 2} m_{g} \cdot c^{2} \sqrt{1-\left(\frac{v}{c}\right)^{2}} d t$

However, the integral of $\delta=\int_{\mathrm{t} 1}^{\mathrm{t} 2} \mathrm{~m}_{\mathrm{g}} \cdot \mathrm{c}^{2} \sqrt{1-\left(\frac{\mathrm{v}}{\mathrm{c}}\right)^{2}} \mathrm{dt}$ is preceded by the plus sign as it cannot have a minimum. Thus, the integrand of Equation (2) must always be positive. Therefore, if $\mathrm{m}_{\mathrm{g}}>0$ then $\mathrm{t}>0$.

We know that the momentum $\overrightarrow{\mathrm{p}}=\frac{\overrightarrow{\partial \mathrm{L}}}{\partial \mathrm{r}}$ and $\mathrm{L}=-\mathrm{m}_{\mathrm{g}} \cdot \mathrm{c}^{2} \sqrt{1-\left(\frac{\mathrm{v}}{\mathrm{c}}\right)^{2}}$.

$\therefore \overrightarrow{\mathrm{p}}=\frac{\mathrm{m}_{\mathrm{g}}}{\sqrt{1-\left(\frac{\mathrm{v}}{\mathrm{c}}\right)^{2}}}=\mathrm{m}_{\mathrm{g}} \overrightarrow{\mathrm{V}}$

The inertial force $\mathrm{F}_{\mathrm{i}}=\overrightarrow{\mathrm{dp}} / \mathrm{dt}$ which acts on the particle in two ways:

1. $\mathrm{F}_{\mathrm{i}}$ is perpendicular to speed

$$
\mathrm{F}_{\mathrm{i}}=\frac{\mathrm{m}_{\mathrm{g}}}{\sqrt{1-\left(\frac{\mathrm{v}}{\mathrm{c}}\right)^{2}}} \frac{\overrightarrow{\mathrm{dv}}}{\mathrm{dt}}
$$

2. $F_{i}$ is in direction of speed

$$
\mathrm{F}_{\mathrm{i}}=\frac{\mathrm{m}_{\mathrm{g}}}{\left\{\sqrt{1-\left(\frac{\mathrm{v}}{\mathrm{c}}\right)^{2}}\right\}^{\frac{3}{2}}} \frac{\overrightarrow{\mathrm{dv}}}{\mathrm{dt}}
$$

The energy of the particle is given by:

$$
E_{g}=\vec{p} \vec{v}-L=\frac{m_{g} c^{2}}{\sqrt{1-\left(\frac{v}{c}\right)^{2}}} \text { or } E_{g}=m_{g} \cdot c^{2}
$$

The introduction of $\mathrm{E}_{\mathrm{g}}$ serves no other purpose than to facilitate the description of the totality.

At rest, the particle's gravitational potential energy is $E_{g o}=m_{g} \cdot c^{2}$

Equation (7) can be represented in the manipulated form as:

$$
\begin{aligned}
& \mathrm{E}_{\mathrm{g}}=\mathrm{m}_{\mathrm{g}} \mathrm{c}^{2}-\frac{\mathrm{m}_{\mathrm{g}} \mathrm{c}^{2}}{\sqrt{1-\left(\frac{\mathrm{v}}{\mathrm{c}}\right)^{2}}}-\mathrm{m}_{\mathrm{g}} \mathrm{c}^{2} \\
& =\frac{\mathrm{m}_{\mathrm{g}}}{\mathrm{m}_{\mathrm{i}}}\left[\mathrm{m}_{\mathrm{i}} \mathrm{c}^{2}+\left[\frac{\mathrm{m}_{\mathrm{i}} \mathrm{c}^{2}}{\sqrt{1-\left(\frac{\mathrm{v}}{\mathrm{c}}\right)^{2}}}-\mathrm{m}_{\mathrm{i}} \mathrm{c}^{2}\right]\right]=\frac{\mathrm{m}_{\mathrm{g}}}{\mathrm{m}_{\mathrm{i}}}\left(\mathrm{E}_{\mathrm{io}}+\mathrm{E}_{\mathrm{ki}}\right) \frac{\mathrm{m}_{\mathrm{g}}}{\mathrm{m}_{\mathrm{i}}} \mathrm{E}_{\mathrm{i}}
\end{aligned}
$$

In analogy with the gravitational energy at rest, the inertial energy at rest $E_{i 0}=m_{i} c^{2}$. Thus, the total inertial energy is $E_{i}=E_{i o}+E_{k i}\left(E_{k i}=\right.$ Kinetic inertial energy).
From Equations (6 and 8),

$\mathrm{E}_{\mathrm{i}}=\frac{\mathrm{m}_{\mathrm{i}} \mathrm{c}^{2}}{\sqrt{1-\left(\frac{\mathrm{v}}{\mathrm{c}}\right)^{2}}}=\mathrm{m}_{\mathrm{i}} \mathrm{c}^{2}$

For $v<<c, E_{i}=m_{i} c^{2}+1 / 2 m_{i} v^{2}$

Comparing Equations (6 and 8)

$\mathrm{E}_{\mathrm{kg}}=\frac{\mathrm{m}_{\mathrm{g}}}{\mathrm{m}_{\mathrm{i}}} \mathrm{E}_{\mathrm{ki}}$

Gravitational field produced by a particle of gravitational mass $m_{g}$ depends on the particle's gravitational energy $\mathrm{E}_{\mathrm{g}}$. For this, we can write as:

$\mathrm{g}=-\frac{\mathrm{GE}_{\mathrm{g}}}{\mathrm{r}^{2} \mathrm{c}^{2}}=-\frac{\mathrm{Gm}_{\mathrm{g}} \mathrm{c}^{2}}{\mathrm{r}^{2} \mathrm{c}^{2}}=-\frac{\mathrm{Gm}_{\mathrm{g}}}{\mathrm{r}^{2}}$

Where, $\mathrm{m}_{\mathrm{g}}$ is the relativistic gravitational mass.

Since it is well known that gravitational force is conservative. Thus, the argument of the above condition can be expressed as:

$E_{g}=-E_{i}$

Thus,

$\mathrm{E}_{\mathrm{i}}=\mathrm{E}_{\mathrm{io}}+\mathrm{E}_{\mathrm{i}}$ and $\mathrm{E}_{\mathrm{g}}=\mathrm{E}_{\mathrm{go}}+\mathrm{E}_{\mathrm{g}}=\mathrm{E}_{\mathrm{go}}-\mathrm{E}_{\mathrm{i}}$

$\mathrm{E}_{\mathrm{g}}+\mathrm{E}_{\mathrm{i}}=\mathrm{E}_{\mathrm{go}}+\mathrm{E}_{\mathrm{io}}$

Comparing between Equations (6 and 8) reveals that $\mathrm{E}_{\mathrm{g} 0}=\mathrm{E}_{\mathrm{i} 0}$ as a consequence of which,

$\mathrm{E}_{\mathrm{g}}+\mathrm{E}_{\mathrm{i}}=\mathrm{E}_{\mathrm{go}}+\mathrm{E}_{\mathrm{io}}=2 \mathrm{E}_{\mathrm{io}}$

However, $\mathrm{E}_{\mathrm{i}}=\mathrm{E}_{\mathrm{i} 0}+\mathrm{E}_{\mathrm{ki}}$. Therefore, Equation (16) can be written as:

$\mathrm{E}_{\mathrm{g}}=\mathrm{E}_{\mathrm{io}}-\mathrm{E}_{\mathrm{k} i}$

Substituting $\mathrm{E}_{\mathrm{io}}=\mathrm{E}_{\mathrm{i}}-\mathrm{E}_{\mathrm{ki}}$ gives:

$\mathrm{E}_{\mathrm{i}}-\mathrm{E}_{\mathrm{g}}=2 \mathrm{E}_{\mathrm{ki}}$

The correlation between gravitational energy and momentum can be derived by squaring and comparing Equations ( 3 and 6 ).

$\frac{\mathrm{E}_{\mathrm{g}}^{2}}{\mathrm{c}^{2}}=\mathrm{p}^{2}+\mathrm{m}_{\mathrm{g}}^{2}$

The Hamiltonian function can be expressed as:

$\mathrm{H}=\mathrm{c} \sqrt{\mathrm{p}^{2}+\mathrm{m}_{\mathrm{g}}^{2} \mathrm{c}^{2}}$

We may now look upon objective to distinguish gravitational Hamiltonian $\mathrm{H}_{\mathrm{g}}$ from inertial Hamiltonian $\mathrm{H}_{\mathrm{i}}$.

$H_{i}=c \sqrt{p^{2}-m_{i}^{2} c^{2}}$

As a direct consequence of it, Equation (17) can be written as:

$\mathrm{H}_{\mathrm{i}}+\mathrm{H}_{\mathrm{g}}=\mathrm{H}_{\mathrm{i}}$ 
The momentum variation yields $\mathrm{H}_{\mathrm{i}}$ variation.

$$
H_{i}=\sqrt{(p+p)^{2} c^{2}-m_{i}^{2} c^{4}} \sqrt{p^{2} c^{2}-m_{i}^{2} c^{4}}
$$

Substituting Equations $(19,34,36)$ into (35) and putting $\mathrm{p}=0$.

$$
\mathrm{m}_{\mathrm{g}}^{2} \mathrm{c}^{2}+\mathrm{m}_{\mathrm{i}}^{2} \mathrm{c}^{2}=2\left(\sqrt{\mathrm{p}^{2} \mathrm{c}^{2}-\mathrm{m}_{\mathrm{i}}^{2} \mathrm{c}^{4}}-\mathrm{m}_{\mathrm{i}}^{2} \mathrm{c}^{2}\right)
$$

Thus, the generalized equation between gravitational and inertial mass is given as:

$$
\mathrm{m}_{\mathrm{g}}=\mathrm{m}_{\mathrm{i}}-2\left[\sqrt{1-\left(\frac{\mathrm{p}}{\mathrm{m}_{\mathrm{i}} \mathrm{c}}\right)^{2}}-1\right] \mathrm{m}_{\mathrm{i}}
$$

Also, for $\mathrm{p}>\mathrm{m}_{\mathrm{i}} \mathrm{c}(\sqrt{5} / 2) ; \mathrm{m}_{\mathrm{g}}$ will be negative.

Therefore, Equation (37) can be written in the form:

$$
(p+p)=\frac{\left(m_{g}-m_{g}\right)(v+v)}{\sqrt{1 v^{(v+v)^{2} / 2}}}
$$

For $\mathrm{v}=0, \mathrm{p}=0$. Therefore, above equation reduced to:

$$
\mathrm{p}=\frac{\left(\mathrm{m}_{\mathrm{g}}-\mathrm{m}_{\mathrm{g}}\right) \mathrm{v}}{\sqrt{1-\mathrm{v}^{2} / \mathrm{c}^{2}}}
$$

From Equation (15), we obtain

$\mathrm{E}_{\mathrm{g}}=2 \mathrm{E}_{\mathrm{io}}-\mathrm{E}_{\mathrm{i}}=2 \mathrm{E}_{\mathrm{io}}-\left(\mathrm{E}_{\mathrm{io}}+\mathrm{E}_{\mathrm{i}}\right)=\mathrm{E}_{\mathrm{io}}+\mathrm{E}_{\mathrm{i}}$

But from Equation (13) $-\mathrm{E}_{\mathrm{i}}=\mathrm{E}_{\mathrm{g}}$

Therefore, $\mathrm{E}_{\mathrm{g}}=\mathrm{E}_{\mathrm{io}}+\mathrm{E}_{\mathrm{g}}$ or $\mathrm{m}_{\mathrm{g}}=\mathrm{m}_{\mathrm{i}}+\mathrm{m}_{\mathrm{g}}$. Replacing $\mathrm{m}_{\mathrm{g}}+\mathrm{m}_{\mathrm{g}}$ by $\mathrm{m}_{\mathrm{i}}$ in above equation, we obtain:

$\mathrm{p}=\mathrm{m}_{\mathrm{i}} \frac{\mathrm{v}}{\sqrt{1=\mathrm{v}^{2} / \mathrm{c}^{2}}}$ or $\frac{\mathrm{p}}{\mathrm{m}_{\mathrm{i}} \mathrm{c}}=\frac{\mathrm{v} / \mathrm{c}}{\sqrt{1 \mathrm{v}^{2} / \mathrm{c}^{2}}}$

Substituting the value so obtained in Equation $(37) \mathrm{m}_{\mathrm{g}}=\mathrm{m}_{\mathrm{i}}-2[-1] \mathrm{m}_{\mathrm{i}}$

Put $v=0$, we get,

$\mathrm{m}_{\mathrm{g}}=\mathrm{m}_{\mathrm{i}}$

It follows that the same as been done previously that $\mathrm{m}_{\mathrm{g}}=\mathrm{n}^{2} \mathrm{~m}_{\mathrm{g}(\mathrm{min})}$ becomes $\mathrm{m}_{\mathrm{i}}=\mathrm{n}^{2} \mathrm{~m}_{\mathrm{i}(\min )}$

$\mathrm{F}_{\mathrm{i}}=\mathrm{m}_{\mathrm{i}} \overrightarrow{\mathrm{a}}$ is the inertial force and $\mathrm{F}_{\mathrm{g}}=\mathrm{m}_{\mathrm{g}} \overrightarrow{\mathrm{g}}$ is the gravitational forces. We already had proven $\mathrm{m}_{\mathrm{g}}=\mathrm{m}_{\mathrm{i}}$. From Equation (5) and (12),

$$
\begin{aligned}
& \frac{\mathrm{m}_{\mathrm{g}}}{\left(1 .\left(\frac{\mathrm{v}}{\mathrm{c}}\right)^{2}\right)^{\frac{3}{2}}} \overrightarrow{\mathrm{a}}=\mathrm{G} \frac{\mathrm{m}_{\mathrm{g}}}{\mathrm{r}^{\prime}\left(\sqrt{1^{\prime}\left(\frac{\mathrm{v}}{\mathrm{c}}\right)^{2}}\right)^{2}} \frac{\mathrm{m}_{\mathrm{g}}}{\sqrt{1^{\prime}\left(\frac{\mathrm{v}}{\mathrm{c}}\right)^{2}}}=\left[\frac{\mathrm{Gm}_{\mathrm{g}}}{\mathrm{r}^{2}}\right] \frac{\mathrm{m}_{\mathrm{g}}}{\left(1^{\prime}\left(\frac{\mathrm{v}}{\mathrm{c}}\right)^{2}\right)^{\frac{3}{2}}} \\
& =\overrightarrow{\mathrm{g}} \frac{\mathrm{m}_{\mathrm{g}}}{3} \\
& \left(1\left(\frac{\mathrm{v}}{\mathrm{c}}\right)^{2}\right)^{\frac{3}{2}}
\end{aligned}
$$

\section{$\overrightarrow{\mathrm{a}}=\overrightarrow{\mathrm{g}}$}

Thus, the rule of equivalence is preserved. Finally, by dividing both members of equation (23) by $\sqrt{1-\left(\frac{\mathrm{v}}{\mathrm{c}}\right)^{2}}$ we
readily obtain:

$M_{g}=M_{i}-2\left[\sqrt{12\left(\frac{p}{m_{i} c}\right)^{2}}-1\right] M_{i}$

In particular, we can look on the momentum variation (p) as due to absorption or emission of electromagnetic energy by the particle (by means of radiation and/or by means of Lorentz's force upon the charge of the particle). In the case of radiation (any type), (p) can be obtained as follows. It is known that the radiation pressure, $\mathrm{dP}$, upon an area $\mathrm{dA}=\mathrm{dxdy}$ of a volume $\mathrm{dV}=\mathrm{dxdydz}$ of a particle (the incident radiation normal to the surface $d A$ ) is equal to the energy $d U$ absorbed per unit volume $\mathrm{dU} / \mathrm{dV}$,

i.e., $d P=\frac{d U}{d V}=\frac{d U}{d A d z}$

Substitution of $\mathrm{v} \mathrm{dz} / \mathrm{dt}$ ( $\mathrm{v}$ is the speed of radiation) into the equation above gives:

$\mathrm{dP}=\frac{\mathrm{dU}}{\mathrm{dV}}=\frac{\frac{\mathrm{dU}}{\mathrm{dAdt}}}{\mathrm{v}} \frac{\mathrm{dD}}{\mathrm{v}}$

Since $d P d A=d F$, we can write:

$\mathrm{dFdt}=\frac{\mathrm{dU}}{\mathrm{v}}$

However, we know that $\mathrm{dF}=\mathrm{dp} / \mathrm{dt}$, then,

$\mathrm{dp}=\frac{\mathrm{dU}}{\mathrm{V}}$

From equation (30), $d U=d P d V=\frac{d V d D}{v}$

Substitution into (32) yields $d p=\frac{d V d D}{v^{2}}$

or

$\int_{0}^{\mathrm{p}} \mathrm{dp}=\frac{1}{\mathrm{v}^{2}} \int_{0}^{\mathrm{V}} \mathrm{dV} \int_{0}^{\mathrm{D}} \mathrm{dD}$

Hence, $p=\frac{V D}{v^{2}}(36)$ from Equation (36) follows that $p=\frac{U}{c} \frac{c}{v}=\frac{U \mu}{c}$.

$\mu=$ The index of refraction.

Substitution into Equation (27) yields $M_{g}=M_{i}-2\left[\sqrt{12\left(\frac{U \mu}{m_{i} c^{2}}\right)^{2}}-1\right] M_{i}$

Deducing the entropy differential equation starting from the Equation (35). Comparison of the Equations (35) and (27) shows that $\mathrm{U} \mu=\mathrm{p}$ c. For small velocities $(\mathrm{V}<<\mathrm{mc}), \mathrm{p}<<\mathrm{m}_{\mathrm{i}} \mathrm{c}$ so that $\mathrm{U}<<\mathrm{m}_{\mathrm{i}} \mathrm{c}^{2}$. Under these circumstances, the development of the Equation (35) in power of $\mathrm{U} \mu / \mathrm{m}_{\mathrm{i}} \mathrm{c}^{2}$, gives, 
$\mathrm{m}_{\mathrm{g}}=\mathrm{m}_{\mathrm{i}}-\left(\frac{\mathrm{U} \mu}{\mathrm{m}_{\mathrm{i}} \mathrm{c}^{2}}\right)^{2} \mathrm{~m}_{\mathrm{i}}$

In the particular case of thermal radiation, it is usual to relate the energy of the photons to temperature, through the relationship $\mathrm{h} v \approx \mathrm{kT}$ where $\mathrm{k}$ is the Boltzmann's constant. Thus, in that case, the energy absorbed by the particle will be $U=\eta \mathrm{h} v \approx \eta \mathrm{kT}$, where $\eta$ is a particle-dependent absorption/emission coefficient. Therefore, Equation (50) may be rewritten in the following form:

$\mathrm{m}_{\mathrm{g}}=\mathrm{m}_{\mathrm{i}}-\left(\frac{\mu \mathrm{k} \eta}{\mathrm{m}_{\mathrm{i}}}\right) \frac{\mathrm{T}^{2}}{\mathrm{c}^{2}} \mathrm{~m}_{\mathrm{i}}$

For electrons at $\mathrm{T}=300 \mathrm{~K}$, we have $\left(\frac{\mu \mathrm{k} \eta}{\mathrm{m}_{\mathrm{i}}}\right) \frac{\mathrm{T}^{2}}{\mathrm{c}^{2}}=10^{-17}$ comparing Equation (37) with Equation (17), we obtain:

$\mathrm{E}_{\mathrm{ki}}=\frac{1}{2}\left(\frac{\mu \mathrm{k} \eta}{\mathrm{c}}\right){\frac{\mathrm{T}}{\mathrm{m}_{\mathrm{i}}^{2}}}^{2}$

The derivative of with $\mathrm{E}_{\mathrm{ki}}$ respect to temperature $\mathrm{T}$ is,

$\frac{\partial \mathrm{E}_{\mathrm{ki}}}{\partial \mathrm{T}}=\left(\frac{\mu \mathrm{k} \eta}{\mathrm{c}}\right)^{2} \frac{\mathrm{T}}{\mathrm{m}_{\mathrm{i}}}$

Thus, substitution of $\mathrm{E}_{\mathrm{ki}}=\mathrm{E}_{\mathrm{i}} \mathrm{E}_{\mathrm{i} 0}$ into (39) gives $\mathrm{T}\left(\frac{\partial \mathrm{E}_{\mathrm{i}}}{\partial \mathrm{T}}+\frac{\partial \mathrm{E}_{\mathrm{i} 0}}{\partial \mathrm{T}}\right)=(\mu \mathrm{k \eta})^{2} / \mathrm{m}_{\mathrm{i}} \mathrm{c}^{2}$ (40) by comparing the Equations (40) and (38) and considering $\frac{\partial \mathrm{E}_{\mathrm{i} 0}}{\partial \mathrm{T}}=0$ that because $\mathrm{E}_{\mathrm{io}}$ does not depend on $\mathrm{T}$, the Equation (38) reduces to:

$\mathrm{T} \frac{\partial \mathrm{E}_{\mathrm{i}}}{\partial \mathrm{T}}=2 \mathrm{E}_{\mathrm{ki}}$

From Equation (17), therefore,

$$
\mathrm{E}_{\mathrm{g}}=\mathrm{E}_{\mathrm{i}}-\mathrm{T} \frac{\partial \mathrm{E}_{\mathrm{i}}}{\partial \mathrm{T}}
$$

Here, we can identify the energy $E_{i}$ with the free energy of the system - F and $E_{g}$ with the internal energy of the system - $U$, thus we can write the Equation (42) in the following form:

$$
\mathrm{U}=\mathrm{F}-\mathrm{T} \frac{\partial \mathrm{F}}{\partial \mathrm{T}}
$$

This is the well-known equation of thermodynamics. On the other hand, remembering:

$\partial \Theta=\partial \tau+\partial \mathrm{U}\left(1^{\text {st }}\right.$ principle of thermodynamics $)$ and,

$\mathrm{F}=\mathrm{U}-\mathrm{TS}$

(44) (Helmholtz’s function),

We can easily obtain from (43), the following equation:

$$
\partial \Theta=\partial \tau+\mathrm{T} \partial \mathrm{U} \Sigma
$$

for isolated systems, $\partial \tau=0$, we thus have $\partial Q=T \partial S(45)$. Which is the wellknown entropy differential equation.

\section{GRAVITATIONAL RELATIVISTIC THERMODYNAMIC}

From the lead of Saslaw and Hamilton [6], we start with a general pair of equations of state for the internal energy $U$ and the pressure P:
$\mathrm{U}=\frac{3}{2} \mathrm{NT}(1-2 \mathrm{~b})$

$\mathrm{P}=\frac{\mathrm{NT}}{\mathrm{V}}(1-\mathrm{b})$

Thus, the above two equations represent the equations of state (e.g., Hill, 1956) [2], Where, the $b$ is dimensionless parameter.

$\mathrm{b}=\frac{2 \pi \mathrm{Gm}^{2} \overline{\mathrm{n}}}{3 \mathrm{~T}} \int_{\mathrm{V}} \xi_{2}(\overline{\mathrm{n}}, \mathrm{T}, \mathrm{r}) \mathrm{r} \mathrm{dr}$

Here, $\overline{\mathrm{n}}=\mathrm{N} / \mathrm{V}$ is the average number density of the system of particles each of mass $\mathrm{m}$. $\mathrm{T}$ is the temperature, $\mathrm{V}$ the volume, $\mathrm{G}$ is the universal constant of gravitation, $\xi_{2}(n, T, r)$ is the two-particle correlation function, and $r$ the distance. These expressions assume a large volume $\mathrm{V}$ for their validity.

The thermodynamic parameters $\mathrm{P}, \mathrm{V}$, and $\mathrm{T}$ are related by $\mathrm{P}=\mathrm{P}(\mathrm{V}, \mathrm{T})$ and $\mathrm{U}=\mathrm{U}(\mathrm{V}, \mathrm{T})$

From the first law of thermodynamics, for any system we have,

$d Q=d U+P d V$

Where $\mathrm{dQ}$ is the amount of heat flowing into the system, $\mathrm{dU}$ is the gain in its internal energy, and PdV is the work done by the system as its volume increases by the infinitesimal amount $\mathrm{dV}$ under the internal pressure P.

$\mathrm{dU}=\left(\frac{\partial \mathrm{U}}{\partial \mathrm{V}}\right)_{\mathrm{T}} \mathrm{dV}+\left(\frac{\partial \mathrm{U}}{\partial \mathrm{T}}\right)_{\mathrm{V}} \mathrm{dT}$

Hence, equation (63) becomes: $d Q=\left[\frac{\partial U}{\partial V}+P(V, T)\right] d V+\frac{\partial U}{\partial T} d T$

From equation (59),

$\mathrm{dS}=\frac{\mathrm{dQ}}{\mathrm{T}}$

The combination of equation (52) with equation (51) leads to:

$\mathrm{dS}=\frac{\mathrm{dQ}}{\mathrm{T}}=\frac{1}{\mathrm{~T}}\left[\frac{\partial \mathrm{U}}{\partial \mathrm{V}}+\mathrm{P}(\mathrm{V}, \mathrm{T})\right] \mathrm{dV}+\frac{\partial \mathrm{U}}{\partial \mathrm{T}} \mathrm{dT}$

Since it is already known that dS is a perfect differential, therefore we must have

$\frac{\partial}{\partial \mathrm{T}}\left[\frac{1}{\mathrm{~T}}\left(\frac{\partial \mathrm{U}}{\partial \mathrm{V}}\right)+\frac{\mathrm{P}}{\mathrm{T}}\right]=\frac{\partial}{\partial \mathrm{V}}\left[\frac{1}{\mathrm{~T}}\left(\frac{\partial \mathrm{U}}{\partial \mathrm{T}}\right)\right]$

Which implies toward the following equation:

$\left(\frac{\partial U}{\partial V}\right)_{T, N}=\left(\frac{\partial P}{\partial T}\right)_{V, N}-P$

The probability for finding a galaxy in volume $\mathrm{dV}_{1}$ and also one in volume $\mathrm{dV}_{2}$ is related to two-point correlation function $\xi_{2}(\mathrm{r})$ by:

$P_{12}=\bar{n}^{-2}\left[1+\xi_{2}(r)\right] d V_{1} d V_{2}$

In general, $\xi_{2}$ will depend on the absolute positions $r_{1}$ and $r_{2}$ of two volume elements. Now, averaging the overall positions and all directions, then $\xi_{2}$ will become a function only of the separation $\mathrm{r}=\left|\mathrm{r}_{1}-\mathrm{r}_{2}\right|$. For $\xi_{2}(\mathrm{r})$ to provide a good description, the system must be 
statistically homogeneous so that on an average overall, the galaxies in a given volume $V=\left(\frac{4}{3} \pi r^{3}\right)$ will be the same as for any sufficiently large subset of galaxies in the same volume. In the grand canonical ensemble, the two-point correlation function $\xi_{2}$ depends on $\mathrm{n}, \mathrm{T}$ as well as on $\mathrm{r}$. Thus, we may write $\xi_{2}=\xi_{2}(\overline{\mathrm{n}}, \mathrm{T}, \mathrm{r})$

$\mathrm{d} \xi_{2}=\frac{\partial \xi_{2}}{\partial \overline{\mathrm{n}}} \mathrm{d} \overline{\mathrm{n}}+\frac{\partial \xi_{2}}{\partial \mathrm{T}} \mathrm{dT}+\frac{\partial \xi_{2}}{\partial \mathrm{r}} \mathrm{dr}$

$\frac{\mathrm{d} \xi_{2}}{\mathrm{dV}}=\frac{\partial \xi_{2}}{\partial \overline{\mathrm{n}}} \frac{\mathrm{d} \overline{\mathrm{n}}}{\mathrm{dV}}+\frac{\partial \xi_{2}}{\partial \mathrm{T}} \frac{\partial \mathrm{T}}{\mathrm{dV}}+\frac{\partial \xi_{2}}{\partial \mathrm{r}} \frac{\mathrm{dr}}{\mathrm{dV}}$

Using the condition $\frac{\mathrm{dT}}{\mathrm{dV}}=0$

Using equations (60) to (62) in equation (69), we have:

$3 \overline{\mathrm{n}} \frac{\partial \xi_{2}}{\partial \overline{\mathrm{n}}}+\mathrm{T} \frac{\partial \xi_{2}}{\partial \mathrm{T}}-\mathrm{r} \frac{\partial \xi_{2}}{\partial \mathrm{r}}=0$

It is inferred from the Equation (75) which is a first-order partial differential equation for two-point correlation function that it is characterized by number density $\bar{n}$, temperature $T$, and the interparticle distance $r$; therefore, two-point correlation function $\xi_{2}$ will depend on the values of $\bar{n}$ and $T$ for the ensemble as well as on the spatial coordinate $r$ in a statistically homogeneous distribution of galaxies clustering gravitationally in an expanding universe.

The galaxies are the extended structures, therefore, in an expanding universe. Hence, swear in a softening parameter $\in$. Hence, for extended mass distribution, the internal energy $U$ and pressure $P$ can be written as:

$$
\begin{aligned}
& \mathrm{U}_{\text {ext }}=\frac{3}{2} \mathrm{NT}-\frac{2 \pi \mathrm{Gm}^{2} \mathrm{~N}^{2}}{3 \mathrm{~V}^{2}} \int_{\mathrm{V}} \xi_{2}(\overline{\mathrm{n}}, \mathrm{T}, \mathrm{r})\left[1+\frac{\epsilon^{2}}{\mathrm{r}^{2}}\right]^{-\frac{1}{2}} \frac{\mathrm{dV}}{4 \pi \mathrm{r}} \\
& \mathrm{P}_{\text {ext }}=\frac{\mathrm{NT}}{\mathrm{V}}-\frac{2 \pi \mathrm{Gm}^{2} \mathrm{~N}^{2}}{3 \mathrm{~V}^{2}} \int_{\mathrm{V}} \xi_{2}(\overline{\mathrm{n}}, \mathrm{T}, \mathrm{r})\left[1+\frac{\epsilon^{2}}{\mathrm{r}^{2}}\right]^{-\frac{3}{2}} \frac{\mathrm{dV}}{4 \pi \mathrm{r}}
\end{aligned}
$$

Implementing the similar steps earlier followed we will derive the same equation with softening parameter as:

$$
3 \overline{\mathrm{n}} \frac{\partial \xi_{2}}{\partial \overline{\mathrm{n}}}+\mathrm{T} \frac{\mathrm{r}^{2}}{\left(\mathrm{r}^{2}+\epsilon^{2}\right)} \frac{\partial \xi_{2}}{\partial \mathrm{T}}-\mathrm{r} \frac{\partial \xi_{2}}{\partial \mathrm{r}}=0
$$

Equation (78) is a first-order partial differential equation for a twopoint correlation function of galaxies with extended structures' clustering gravitationally. For extended mass structures, the value of $\in$ is taken between 0.01 and 0.05 (in the units of total radius). The thermodynamic description of a two-point correlation function for describing the gravitational interaction of galaxies can be defined by the physical behavior of equations (61) and (64), respectively.

Now, we pose the following set of conditions to portray its generic and operational form.

a. In a homogeneous universe, the limiting values of $\bar{n}, T$, and $r$ are avail by the positive value of $\xi_{2}$.

b. Except for the number density $\bar{n}$, the value of two-particle correlation function $\xi_{2}$ will increase and decrease when $\bar{n}$, T, and $r$ are very small and very large, respectively.

c. Because of virial equilibrium increase of two-particle correlation function divulge that the clustering of galaxies becomes dominant,

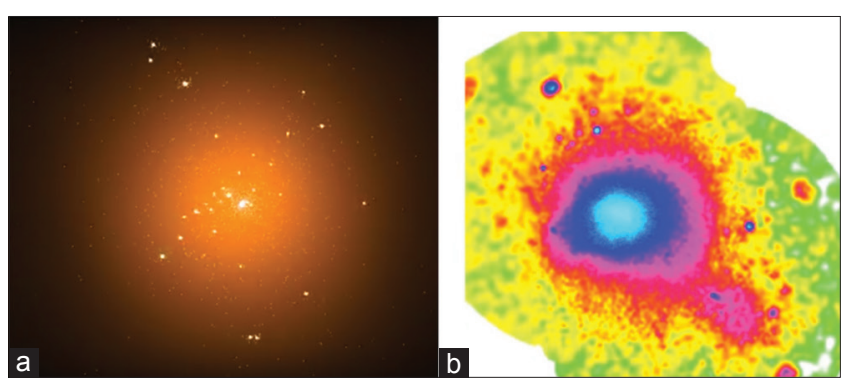

Fig. 1: (a) Computational simulation of the gravitating clusters of galaxies, (b) thermodynamic viewpoint of the given model

which in turn implies that at low temperatures and high densities' more and more clusters are formed.

d. When $\bar{n} T^{-3}$ is very large, the two-particle correlation function will increase, and the measuring correlation parameter $b$ approaches to 1 and vice versa.

Thus, we extend our numerical approach as:

Integrating Equation (75) along with its characteristics as:

$\frac{\mathrm{d} \overline{\mathrm{n}}}{3 \overline{\mathrm{n}}}=\frac{\mathrm{dT}}{\mathrm{T}}=-\frac{\mathrm{dr}}{\mathrm{r}}$

Thus, the result leads to

$b=\frac{\beta \bar{n} T^{-3}}{1+\beta \bar{n} T^{-3}}$

This is the equation to be used for the thermodynamic dependence of $b$. Thus, we showed that the solution a two-particle correlation function is self-solicit and b demonstrates its complete dependence on $\bar{n} T^{-3}$.

\section{VALIDATING RELATIVISTIC GRAVITATIONAL THERMODYNAMICS}

The two-point correlation function in a gravitational galaxy clustering obeys power law Peebles (1980), which has also been confirmed from $\mathrm{N}$-body computer simulations (Itoh et al., 1993) and is written as:

$\xi_{2}=r^{-1.8}$

From equation (62), we can write

$\frac{\partial \overline{\mathrm{n}}}{\partial \mathrm{V}}\left[\frac{\partial \mathrm{b}}{\partial \overline{\mathrm{n}}}-\frac{\mathrm{b}}{\overline{\mathrm{n}}}\right]=\frac{2 \mathrm{~m}^{2} \overline{\mathrm{n}}}{3 \mathrm{~T}} \frac{\xi_{2}(\overline{\mathrm{n}}, \mathrm{T}, \mathrm{r})}{4 \mathrm{~T}}$

The regular form of $b$ by Saslaw and Hamilton [6] is described by equation (69)

$\left\{\begin{array}{c}\frac{\partial \mathrm{b}}{\partial \overline{\mathrm{n}}}=\frac{\mathrm{b}(1 \mathrm{bb})}{\overline{\mathrm{n}}} \\ \frac{\partial \overline{\mathrm{n}}}{\partial \mathrm{V}}=\mathrm{V} \frac{\overline{\mathrm{n}}}{\mathrm{V}}\end{array}\right.$

The substitution of equation (72) in (71) gives the modified form of equation (84) as:

$\xi_{2}=r^{-2.0}$

This shows that the power law for a two-point correlation function developed is in close agreement with Peebles law and hence confirms the applicability of relativistic gravitational thermodynamics used to study the two-point correlation function for understanding gravitational clustering of galaxies in an expanding universe. The 
computational view of the given model is shown below in Fig. $1 \mathrm{~A}$ and $B$.

\section{CONCLUSION}

We put-forth relativistic gravitational thermodynamic methodology wherein the dependence of $\xi_{2}$ on $\bar{n}, \mathrm{~T}$, and $r$ highlighted. One of the most excel features of the results is its facility to extend $\xi_{2}$ to higher order correlations. Unlike the point mass system in expanding universe with the insertion of softening parameter $\epsilon$, it's appropriateness to extended structures will give an edge toward the study of extensive structure of universe.

\section{REFERENCES}

1. Aguirre A, Schaye J, Hernquist L, Kay S, Springel V, Theuns T, et al. Confronting cosmological simulations with observations of intergalactic metals. Astrophys J Lett 2005;620(1):L13.

2. Hill TL. Statistical Mechanics: Principles and Selected Applications. New York: McGraw-Hill; 1956.

3. Tozzi P, Norman C. The evolution of X-ray clusters and the entropy of the intracluster medium. Astrophys J 2001;546(1):63.

4. Peebles PJ. The Large Scale Structure of the Universe. Princeton: Princeton University Press; 1980.

5. Brüggen M, Kaiser CR, Churazov E, Enblin TA. Simulation of radio plasma in clusters of galaxies. Mon Not R Astron Soc
2002;331(3):545-55.

6. Cavaliere A, Fusco-Femiano R. X-rays from hot plasma in clusters of galaxies. Astron Astrophys 1976;49:137-44.

7. Reynolds CS, Heinz S, Begelman MC. The hydrodynamics of dead radio galaxies. Mon Not R Astron Soc 2002;332(2):271-82.

8. Percival WJ, Nichol RC, Eisenstein DJ, Frieman JA, Fukugita M, Loveday $\mathrm{J}$, et al. On the stellar populations in faint red galaxies in the hubble ultra deep field. Astrophys J 2007;657:645.

9. Cole S, Percival WJ, Peacock JA, Norberg P, Baugh CM, Frenk CS, et al. The 2dF GRS Collaboration. Mon Not Roy Astron Soc 2005;362:505.

10. MatsubaraT. Phys Rev D 2011;69:083518.

11. Rai A. Shell implementation of neural net over the UNIX environment for file management: A step towards automated operating system. J Oper Syst Dev Trends 2014;1(2):10-4.

12. Rai A. Automation of community from cloud computing. J Adv Shell Program 2014;1(1):21-3.

13. Rai A. Dynamic data flow based spatial sorting method for GPUs: Software based autonomous parallelization. Recent Trends Parallel Comput 2014;1(1):15-8.

14. Rai A. Dynamic pagination for efficient memory management over distributed computational architecture for swarm robotics. J Adv Shell Program 2014;1(2):1-4.

15. Rai A, Ramanathan S, Kannan RJ. Quasi Opportunistic Supercomputing for Geospatial Socially Networked Mobile Devices. Enabling Technologies: Infrastructure for Collaborative Enterprises (WETICE), 2016 IEEE $25^{\text {th }}$ International Conference on IEEE; 2016. 